\title{
A Politização do Sangue no Primeiro Mundo*
}

\author{
LUIZ A. DE CASTRO SANTOS \\ CLAUDIA MORAES \\ VERA SCHATTAN P. COELHO ${ }^{* *}$
}

A quem acompanhou os debates da Constituinte de $1988 \mathrm{em}$ torno dos rumos da hemoterapia no Brasil, pareceria que a definição de tais rumos nunca dependeu tanto da ação da sociedade civil organizada e do Parlamento e tão pouco da iniciativa "tecnocrática" do aparelho burocrático do Estado. Pois essa primeira impressão de um observador interessado, por certo, corresponderia à realidade dos fatos. Decorridos alguns anos desde a Assembléia Constituinte, não resta dúvida, hoje, de que as discussões e debates que desaguaram no parágrafo 4 do Artigo $199^{1}$ e, mais que isto, a própria

* Este é o terceiro trabalho que dedicamos à discussão da política hemoterápica, com base em pesquisa conduzida no Cebrap, em São Paulo, entre 1988-89, financiada em duas fases pela Finep e pela Secretaria de Ciência e Tecnologia do Estado de São Paulo. Os autores são inteiramente responsáveis pelas análises e conclusões apresentadas. Os artigos anteriores também foram publicados em Physis, vol. I, n ${ }^{0} 1,1991$ e vol. II, n ${ }^{0} 1,1992$.

** Luiz Antonio de Castro Santos é professor adjunto do Departamento de Ciências Humanas e Saúde do IMS/UERJ e pesquisador licenciado do Cebrap; Cláudia Moraes é antropóloga e economista; e Vera Schattan Pereira Coelho é pesquisadora do NEPP/Unicamp e consultora da Fundap.

1 O Artigo 199 dispõe: “A assistência à saúde é livre à iniciativa privada". E o parágrafo 4: "A lei disporá sobre as condições e os requisitos que facilitem a remoção de órgãos, tecidos e substâncias humanas para fins de transplante, pesquisa e tratamento, bem como a coleta, processamento e transfusão de sangue e seus derivados, sendo vedado todo tipo de comercialização". 
inserção da hemoterapia como matéria constitucional, refletiram as pressões ou o lobby de grupos organizados da sociedade civil sobre o próprio Parlamento. Entre esses grupos se destacaram o Grupo de Apoio à Prevenção à Aids - GAPA, criado em São Paulo em 1985, e a Associação Brasileira Interdisciplinar de Aids - ABIA, organizada no Rio de Janeiro, em 1986, como parte de um movimento de politização nacional da "questão do sangue". 2 Essas indicações iniciais sobre o panorama geral brasileiro, retomadas a seguir, servirão como referência para que situemos, mais à frente, o contexto internacional da hemoterapia.

No caso brasileiro, longe de nós imaginar que, antes de 1988, as políticas públicas para o setor resultaram de um processo decisório autônomo - isto é, inteiramente livre de pressões dos grupos de interesse. Nesse sentido procuramos demonstrar, no artigo anteriormente citado, que o PróSangue de 1980 - uma política governamental decisiva para a hemoterapia brasileira - foi uma resposta (ainda que tímida) aos reclamos da sociedade, particularmente da corporação médica, diante do crescente descontrole das atividades hemoterápicas no País, dos altíssimos índices da doença de Chagas e de hepatite transfusional etc.

O que aqui sugerimos é a grande autonomia das instâncias do Executivo federal diante das pressões da sociedade civil, pelo menos até 1980. Mesmo os setores empresariais, tidos por algumas correntes políticas como os responsáveis pelos desatinos da hemoterapia nacional, só acumularam poderes na produção de hemoderivados, área específica na qual podem ter contagiado (em todos os sentidos da palavra) as decisões governamentais.

Um conhecedor do quadro trágico que se delineou no Rio de Janeiro, particularmente na Baixada Fluminense - onde a obtenção e a comercialização do sangue caíram nas mãos de contraventores e viraram caso de polícia —, diria logo que não só os interesses do setor de hemoderivados se fizeram ouvir em Brasília, mas os dos empresários de modo geral. A esse argumento. no entanto, se deve contrapor um outro: na verdade, as instâncias estaduais de poder foram permeáveis a tais interesses, mais localizados. A política nacional para o setor esteve, até o Pró-Sangue, senão até os tempos da Constituinte, muito mais afeita às (in)decisões dos aparatos técnicos dos Ministérios da Saúde e Previdência. Isto ocorreu porque a hemoterapia era uma área pouco estratégica se comparada à preocupação, então vigente, de desmontagem de toda a rede pública hospitalar e de privatização acelerada

2 Cf. L. A. de Castro Santos, C. Moraes e V. S. P. Coelho, "Os Anos 80: A Politização do Sangue", Physis, vol. II, n 1, 1992, pp. 107-49. 
(e inconseqüente) dos serviços de saúde do País. Esses objetivos mais abrangentes, sem dúvida, se fizeram representar em Brasília, só afetando porém. a política hemoterápica (se é que se poderia chamar de "política" a um conjunto desordenado de normas legais) naquilo que ela diretamente dependia de políticas gerais para o "setor saúde". 3

$\mathrm{Na}$ verdade, é a Constituinte que inaugura, de fato e na forma da lei, os novos tempos de participação da sociedade civil nos rumos da hemoterapia - particularmente das organizações não-governamentais como a ABIA, dos movimentos sociais como o Comitê Pacto de Sangue, dos grupos políticopartidários associados à chamada corrente sanitarista —, atuação esta desencadeada em grande parte pelo surgimento da Aids nas grandes cidades brasileiras.

Nos países do Primeiro Mundo não foi outro o impacto causado pela Aids "pós-transfusional": uma presença crescente da sociedade civil na formulação das políticas do sangue e hemoderivados a partir da segunda metade da década de 80 . Se analisarmos a literatura internacional sobre o tema, veremos os reflexos da intensa politização da questão, projetando-a para fora dos círculos do debate técnico ou especializado dos hemoterapeutas, atraindo a atenção de sociólogos e filósofos, economistas e policy analysts.

Mas, desde logo, devem ser salientadas algumas diferenças expressivas entre o Primeiro Mundo e o contexto brasileiro, tanto do ponto de vista da natureza do debate sobre a questão do sangue, como da própria permeabilidade das políticas públicas hemoterápicas às demandas da sociedade civil. Em primeiro lugar, o tema foi alvo de interesse das ciências humanas e da moral philosophy inglesa e norte-americana muito antes do aparecimento da Aids - pelo menos desde o início da década de 70. O que a Aids fez foi revigorar tal debate, sem dúvida alguma de longa tradição naqueles países, mas importante também em outras nações européias além da Inglaterra. Questões de altruísmo e problemas causados por doenças "transfusionais", como a hepatite, estiveram entre os tópicos que atraíram a atenção do Primeiro Mundo há mais de 20 anos. No Brasil o interesse "não-técnico", não-especializado é muito mais recente, e claramente posterior à epidemia da Aids.

3 Um exemplo do tipo de política dependente de políticas globais foi a compra pela Previdência, a partir de 1967, do sangue estocado nos bancos de sangue particulares para ser utilizado nos hospitais públicos e conveniados. Exemplos como esse, todavia, não refletem uma política explícita para a atividade hemoterápica nacional. 
Em segundo lugar, na medida em que a "politização do sangue" no Brasil ganhava os contornos de uma discussão mais ampla sobre Estado e iniciativa privada, intervenção estatal e mercado, socialismo vs. neoliberalismo etc., recebeu desses temas, diferentemente do contexto internacional. um forte componente de radicalização ideológica. Podemos dizer que. em nosso País, a politização do sangue ganha uma dimensão nitidamente ideológica e político-partidária, com suas vantagens (por exemplo, forte apelo à mobilização popular) e desvantagens (questões cruciais. de natureza técnica e organizacional, passam a segundo plano). Entre essas últimas, constata-se que a "ideologização" do tema foi responsável por excluir dos debates e conclusões da Constituinte os hemoterapeutas vinculados ao setor privado de antiga e respeitada tradição profissional no País, principalmente aqueles sediados em São Paulo.

É nesse sentido que a legislação aprovada esteve excessivamente circunscrita às correntes que expressavam posições político-partidárias de forte teor doutrinário, excluindo do cenário, ab initio, atores relevantes do setor (como os hemoterapeutas dos serviços hospitalares) dotados de profundo conhecimento técnico e organizacional. Isso significa. para pôr os pingos nos is, que as políticas públicas hemoterápicas decorrentes da regulamentação da matéria constitucional estarão marcadas por uma restrita permeabilidade à sociedade civil, a não ser que todos os atores até agora excluídos sejam chamados à mesa das deliberações.

Em terceiro lugar, apesar da forte politização do tema no Brasil, que deveria constituir uma garantia de busca da diversidade na pesquisa e de uma abordagem interdisciplinar, é surpreendente o tratamento por assim dizer paroquial das discussões, seja no plano estritamente acadêmico. seja no âmbito do Congresso e dos grupos político-partidários. Para ficarmos no primeiro caso, diferentemente da literatura brasileira. o foco internacional da pesquisa é a tônica da literatura especializada do Primeiro Mundo. Basta, por enquanto, que se cite um estudo clássico, publicado na Inglaterra e nos Estados Unidos em 1971. ${ }^{4}$ no qual as políticas sociais do sangue e o perfil dos doadores de diversos países são examinados em profundidade.

A seguir, este artigo focaliza de perto uma área crucial para a acumulação de conhecimentos no setor, que é o debate acadêmico. Em decorrência do paroquialismo a que nos referimos, a discussão acadêmica internacional é pouquíssimo conhecida no Brasil. 5

4 R. M. Titmuss, The Gift Relationship: From Human Blood to Social Policy, Londres, George Allen \& Unwin e Nova Iorque. Pantheon Books, 1971 
Como salientamos acima, o aparecimento do sangue como objeto de interesse das Ciências Humanas e da Filosofia, na Europa e nos Estados Unidos, data pelo menos de 1970. Entretanto, nossa pesquisa de campo revelou não só um desconhecimento dessa literatura por parte dos profissionais brasileiros vinculados direta ou indiretamente ao tema, como também uma carência surpreendente e preocupante de livros e revistas internacionais sobre o assunto nas bibliotecas especializadas das Faculdades de Medicina e outras instituições médicas e de saúde pública, governamentais e não-governamentais, em São Paulo e no Rio de Janeiro.

Ao discutir, ainda que de modo sumário, alguns tópicos candentes e polêmicos trazidos à tona pela literatura de outros países, nosso trabalho pretende difundir tais questões e lançá-las no interior do debate nacional, às vésperas da revisão ou regulamentação pelo Congresso de matéria constitucional sobre a atividade hemoterápica.

\section{Modelos hemoterápicos em discussão}

Procuramos, nesta seção, orientar uma pesquisa bibliográfica que possibilite conhecer como as atividades e responsabilidades do setor hemoterápico estão divididas entre os setores público e privado em diferentes países do Primeiro Mundo, quais as principais questões que estão sendo levantadas sobre a performance de diferentes modelos hemoterápicos e quais as dimensões técnicas discutidas pela literatura especializada de imediata relevância para o Brasil.

A agenda de pesquisa em países como os Estados Unidos e Inglaterra contempla basicamente variáveis institucionais e técnicas dos sistemas de sangue. As primeiras permitem identificar o organograma e as características do sistema organizacional: se o sistema é composto por serviços autônomos ou coordenados; se coordenados, em que medida se subordinam a uma política centralizadora ou descentralizadora; que serviços são públicos, beneficentes, comunitários ou particulares; se particulares, se estão organizados em bases concorrenciais ou monopolistas; como são indicados os funcionários e diretores dos serviços; que tipo de clientela cada serviço beneficia;

5 Sobre a discussão dos limites estreitos do debate político no Congresso Constituinte, ver L. A. de Castro Santos, C. Moraes e V. S. P. Coelho. "Sangue. Aids e Constituinte: Senso e Contra-Senso", in R. Parker et alli, orgs., A AIDS no Brasil, 1982 a 1992. Rio de Janeiro, Editora Relume-Dumará, 1993. 
e quais os debates sobre a eficiência desses sistemas que mobilizam a sociedade como um todo ou segmentos importantes dela. As variáveis técnicas privilegiam a rotina e alguns dos parâmetros que norteiam o sistema, isto é, como é feita a seleção de doadores, os testes, estocagem, transfusão, tipos de serviços que oferece, custos e estatísticas.

Como se verá a seguir, a pauta de discussões em países desenvolvidos caracteriza-se por um elemento comum, que poderia mesmo ser considerado um quarto ponto de distinção entre a literatura nacional e a dos países do Primeiro Mundo: trata-se do escopo amplo, dos interesses diversificados dessa literatura, que aborda tanto elementos institucionais como técnicos da atividade hemoterápica, além da dimensão sociopolítica.

Pudemos recuperar alguns aspectos dessa visão ampla nos textos produzidos por cientistas sociais desde fins dos anos 60 e aos quais tivemos acesso por meio de pesquisas em bibliotecas norte-americanas. A preocupação central das discussões era a questão da competência e eficiência médicas com julgamentos éticos e morais que tinham a ver com a sociedade como um todo. Com o aparecimento da Aids, várias posições até então defendidas foram revistas. É o caso, por exemplo, dos sistemas centralizados, que se tornaram alvo de críticas bastante severas mas negligenciadas no Brasil. onde uma proposta corrente para o setor é, justamente, desenvolver um sistema dessa natureza.

A politização do sangue no Primeiro Mundo inicia-se na Inglaterra, a partir de um debate amplo sobre o National Health Service, de que faz parte o National Blood Transfusion Centre. Uma vez processado e fracionado o sangue colhido em hemocentros regionais - sempre de doadores não-remunerados - o Centro Nacional de Transfusão de Sangue faz a distribuição gratuita aos hospitais mediante de um sistema de quotas, baseadas em estimativas das necessidades de cada hospital.

Esse sistema suscitou críticas (que ainda perduram, como se verá mais adiante) pois argumentava-se que ele estimularia os hospitais a desperdiçarem sangue. O que os críticos propunham era a venda do sangue aos hospitais, isto é, a adoção de um incentivo financeiro, que, segundo se acreditava, provocaria o uso criterioso e evitaria desperdícios. Esta foi a posição defendida por uma instituição de pesquisas de Londres, o Institute of Economic Affairs, que lançou a polêmica por meio de um estudo de dois economistas de seu staff, M.H. Cooper e A.J. Culyer, em defesa do livre mercado do sangue e hemoderivados. ${ }^{6}$ Os autores defendiam a idéia de que, sendo o sangue um bem escasso, só se conseguiria regular a demanda fazendo-a chegar aos níveis estritamente necessários, na medida em que ele fosse uma 
sangue um bem escasso, só se conseguiria regular a demanda fazendo-a chegar aos níveis estritamente necessários, na medida em que ele fosse uma mercadoria sujeita às leis de mercado. Caso fosse "livre", isto é, suprido por agências estatais ou beneficentes, haveria uma tendência ao desperdício.

Já em 1968, o sociólogo inglês Richard M. Titmuss, da London School of Economics and Political Science, publica um artigo em que rejeita a noção do sangue como mercadoria, e sustenta que o mercado não pode evitar a discriminação e o estigma no acesso a bens essenciais. ${ }^{7}$ Em 1971, Titmuss amplia consideravelmente esse debate, tentando correlacionar cidadania, valores morais e qualidade do sangue transfundido. ${ }^{8} \mathrm{Na}$ análise comparativa entre os sistemas hemoterápicos da Grã-Bretanha e dos Estados Unidos (que incorpora a discussão de outros países, como a União Soviética e a Suécia) há uma preocupação de questionar a medicina privada e a racionalidade das leis de mercado como garantia de melhores serviços. Titmuss procura demonstrar que os sistemas nacionais de sangue em que a doação é voluntária e não-remunerada apresentam índices de hepatite transfusional mais baixos que os sistemas mercantilizados.

Titmuss argumenta, ainda, que o tipo de doação, seja voluntária e não-remunerada, seja remunerada, além de correlacionar-se diretamente com a qualidade do sangue que se obtém, reflete as relações humanas que se desenvolvem em uma sociedade. É também um elemento capaz de influenciar outras áreas da vida social, incentivando comportamentos altruístas, no caso da doação voluntária, ou egoístas, na doação remunerada.

A análise de Titmuss é particularmente crítica em relação aos Estados Unidos, que ele considera dominado em seus serviços transfusionais pelo mercantilismo. Aqui, sua preocupação distingue-se um pouco dos alvos do trabalho de Cooper e Culyer: é a compra de sangue de doadores que está em pauta, mais que a venda de sangue para os hospitais por serviços nacionais. Ainda que possam ser tratadas independentemente, Titmuss aborda essas questões em conjunto, sob a ótica (crítica) do mercantilismo.

Sua ênfase recai sobre os problemas da doação. Para Titmuss, a remuneração estimulava o doador a esconder informações que pudessem excluí-lo

6 M. H. Cooper e A. J. Culyer, "The Price of Blood". Hobart Paper, $n^{\circ} 41$, The Institute of Economic Affairs. Londres, 1968 apud P. D. Shaw. "Medicine and the Market Place", in N. Timms e D. Watson, eds., Philosophy in Social Work, Londres, Routledge and Kegan Paul. 1978

7 Ver R. M. Titmuss. Commitment to Welfare, Londres, George Allen \& Unwin. 1968, cap. 12.

8 R. M. Titmuss, The Gift Relationship..., op. cit. 
os altos índices de hepatite transfusional nos EUA. Na Inglaterra, onde uma pessoa recebia por sua doação uma xícara de chá ou um copo de cerveja, a hepatite não era um problema.

Por mais difícil que seja compreender a doação voluntária como elemento capaz de influenciar outras áreas da vida social ou, como se verá adiante, sustentar que esse tipo de doação garanta por si só menores índices de contaminação transfusional, não deve passar sem menção o forte impacto que a análise de Titmuss causou no debate mundial sobre o tema e sobre a própria qualidade dos sistemas hemoterápicos. Este é um ponto da maior relevância.

Sua repercussão nos EUA, a partir dos primeiros anos da década de 70 , foi tamanha que chega a afetar a estrutura dos bancos de sangue. Em resposta ao clamor de instituições não-lucrativas (como alguns Community Blood Banks) e da opinião pública em geral, o governo federal adota uma política que favorece a doação voluntária de sangue. No plano internacional, as resoluções programáticas da Organização Mundial da Saúde - OMS sobre a "utilização e provisão de produtos sanguíneos de origem humana" (WHA28.72), ${ }^{9}$ adotadas pela $28^{\text {a }}$ Assembléia Mundial da Saúde. de maio de 1975, são um reflexo fiel das idéias e propostas de Titmuss.

A contribuição deste autor foi igualmente inestimável do ponto de vista intelectual. Já em 1972, a Fundação Russell Sage organiza um Encontro, nos Estados Unidos, sugestivamente intitulado Conferência sobre Altruísmo e Teoria Econômica. Nessa ocasião, o economista Kenneth J. Arrow apresenta um trabalho no qual faz uma apreciação respeitosa, porém desfavorável, dos argumentos do sociólogo inglês. ${ }^{10}$

Primeiramente, Arrow mostra-se cético em relação às explicações de Titmuss sobre a doação "altruísta". Titmuss parece sugerir que na Inglaterra os indivíduos doam sangue porque vivem em uma sociedade altruísta, mas não explica por que, nessa sociedade, alguns doam e outros não (apenas $6 \%$ dos ingleses doavam sangue na época da pesquisa de campo). Arrow procura explicações alternativas para a doação: talvez alguém doe para forçar uma "obrigação generalizada" de outras pessoas ou gerações retribuírem quando se tornar necessário (aqui reside uma noção implícita de um contrato social).

9 A Resolução WHA 28.72 está reproduzida em Organización Mundial de la Salud, Toma, Fraccionamiento, Inspección de la Calidad y Usos de la Sangre y de los Productos Sanguineos. Genebra, 1982, p. 2.

10 K. J. Arrow, "Gifts and Exchanges", in M. Cohen et alli, eds., Medicine and Moral Phylosophy, Princeton, Princeton University Press, 1981 
os altos índices de hepatite transfusional nos EUA. Na Inglaterra, onde uma pessoa recebia por sua doação uma xícara de chá ou um copo de cerveja, a hepatite não era um problema.

Por mais difícil que seja compreender a doação voluntária como elemento capaz de influenciar outras áreas da vida social ou, como se verá adiante, sustentar que esse tipo de doação garanta por si só menores índices de contaminação transfusional, não deve passar sem menção o forte impacto que a análise de Titmuss causou no debate mundial sobre o tema e sobre a própria qualidade dos sistemas hemoterápicos. Este é um ponto da maior relevância.

Sua repercussão nos EUA, a partir dos primeiros anos da década de 70 , foi tamanha que chega a afetar a estrutura dos bancos de sangue. Em resposta ao clamor de instituições não-lucrativas (como alguns Community Blood Banks) e da opinião pública em geral, o governo federal adota uma política que favorece a doação voluntária de sangue. No plano internacional, as resoluções programáticas da Organização Mundial da Saúde - OMS sobre a "utilização e provisão de produtos sanguíneos de origem humana" (WHA28.72), ${ }^{9}$ adotadas pela $28^{\text {a }}$ Assembléia Mundial da Saúde, de maio de 1975, são um reflexo fiel das idéias e propostas de Titmuss.

A contribuição deste autor foi igualmente inestimável do ponto de vista intelectual. Já em 1972, a Fundação Russell Sage organiza um Encontro, nos Estados Unidos, sugestivamente intitulado Conferência sobre Altruísmo e Teoria Econômica. Nessa ocasião, o economista Kenneth J. Arrow apresenta um trabalho no qual faz uma apreciação respeitosa, porém desfavorável, dos argumentos do sociólogo inglês. ${ }^{10}$

Primeiramente, Arrow mostra-se cético em relação às explicações de Titmuss sobre a doação "altruísta". Titmuss parece sugerir que na Inglaterra os indivíduos doam sangue porque vivem em uma sociedade altruísta, mas não explica por que, nessa sociedade, alguns doam e outros não (apenas $6 \%$ dos ingleses doavam sangue na época da pesquisa de campo). Arrow procura explicações alternativas para a doação: talvez alguém doe para forçar uma "obrigação generalizada" de outras pessoas ou gerações retribuírem quando se tornar necessário (aqui reside uma noção implícita de um contrato social).

9 A Resolução WHA 28.72 está reproduzida em Organización Mundial de la Salud, Toma, Fraccionamiento, Inspección de la Calidad y Usos de la Sangre y de los Productos Sanguíneos, Genebra, 1982, p. 2.

10 K. J. Arrow, "Gifts and Exchanges", in M. Cohen et alli, eds., Medicine and Moral Phylosophy, Princeton, Princeton University Press, 1981. 
Ou ainda, de uma perspectiva cara aos sociobiólogos, pessoas doam porque o altruísmo seria um mecanismo evolutivo "embutido" nas sociedades humanas, favorecendo a sobrevivência da espécie.

Seja como for, diz Arrow, parece que as sociedades humanas só têm a ganhar se for preservada, em benefício da diversidade, a livre escolha do indivíduo entre doar sangue ou receber por ele uma compensação financeira. Diferentemente de Titmuss, Arrow não acredita que a criação de um mercado para o sangue e hemoderivados possa reduzir o potencial de altruísmo existente em uma sociedade.

Quanto à eficiência do sistema, Arrow lembra que este é ineficente se há outro meio de distribuir um bem como o sangue, de tal maneira que, segundo critérios apropriados, todas as pessoas dele se beneficiem. Titmuss acredita que a remuneração e comercialização do sangue criam três tipos de ineficiência: impõe riscos desnecessários aos receptores de sangue; impõe riscos desnecessários a certas classes de doadores; e impõe o desperdício e a escassez de sangue. (Neste último caso, como o mercado opera segundo uma lógica de interesses empresariais, e não segundo interesses sociais, poderá sobrar sangue em áreas socialmente afluentes, e escassear em áreas pobres.) Arrow, por sua vez, só crê na existência das duas primeiras formas de risco, mas acha que ambas podem ser reduzidas sem a abolição do sistema. Vê na proposta de Titmuss uma confiança excessiva "nos recursos escassos da motivação altruísta" de qualquer sociedade. ${ }^{11}$ Quanto ao terceiro tipo, Arrow acredita que o mercado não é per se uma causa de desperdício; no caso norte-americano, "se houver desperdício", diz ele, deve-se antes à forma excessivamente descentralizada da coleta de sangue do que ao "comercialismo". ${ }^{12}$ (O tema da descentralização será retomado mais adiante.) Arrow encerra habilmente essa discussão: não há alternativas que se excluam, há sistemas que se complementam. O "imperativo categórico" do altruísmo e o mercado podem operar juntos, para benefício de todos.

$\mathrm{O}$ terceiro ponto discutido por Arrow diz respeito à doação como elemento de coesão social. A comercialização do sangue seria acompanhada pelo aumento da hostilidade entre médicos e pacientes, pelo aumento dos processos legais de imperícia (malpractice suits) e por excessivos - não necessariamente melhores - cuidados médicos com o paciente. Arrow argumenta que tampouco na Grã-Bretanha existem remédios eficazes contra 
necessariamente melhores - cuidados médicos com o paciente. Arrow argumenta que tampouco na Grã-Bretanha existem remédios eficazes contra erros médicos e que amorteçam a hostilidade entre médico e paciente. Como o número de doadores é muito reduzido na sociedade inglesa. Arrow ironiza o modelo de sociedade fabiana de Titmuss como se estivesse baseado em uma "aristocracia de santos". Como são raros tais "grupos de status", até que ponto, indaga Arrow, podem as transações comerciais prejudicar o funcionamento da sociabilidade? ${ }^{13}$

Numa réplica em defesa de Titmuss. o cientista político Peter Singer propõe um desafio teórico a Arrow: pode o sangue ser considerado um bem escasso, como, por exemplo, o petróleo ${ }^{14}$ Não constituiria o sangue um caso particular de bem que, quanto mais utilizado, mais se reproduziria? "A mim me parece muito mais difícil agir com consideração pelos outros quando a norma do círculo de pessoas com as quais me relaciono é agir egoisticamente". ${ }^{15}$ Singer cita, em seu apoio, a evidência produzida por certos experimentos de psicologia social sobre comportamento altruísta.

Também em defesa de Titmuss ergue-se o cientista social irlandês $P$. D. Shaw, anos depois da Conferência sobre Altruísmo e Teoria Econômica. ${ }^{16} \mathrm{~A}$ análise de P. D. Shaw repõe certas questões sobre mercado e Estado: inicialmente refere-se à ironia de Arrow sobre a "aristocracia de santos", que doa sangue na Inglaterra. Para Arrow, fora do mercado só há elitismo. Só o mercado garante, no limite, a livre escolha, o acesso livre ao bem escasso. Ora, lembra Shaw. no interior do próprio mercado há relações de poder. É a existência dessas relações de poder, ao estimularem comportamentos não-altruístas, que justifica a preocupação de Shaw (e de Titmuss e Singer) com os efeitos sobre o tecido social de um sistema hemoterápico baseado na comercialização. Daí, argumenta, faz-se necessária a intervenção do Estado, que deverá estabelecer os limites da ação do mercado e "reduzir" a liberdade de escolha das pessoas para vender sangue. Tal procedimento, continua Shaw, permitiria maior difusão de comportamentos altruístas nas sociedades humanas.

Este ponto conduz à outra crítica do argumento de Arrow. Como vimos, é extremamente limitada, para esse autor, a possibilidade de o com-

13 Idem, p. 156.

14 P. Singer, "Altruism and Commerce: A Defense of Titmuss Against Arrow", in M. Cohen et alli, eds., Medicine and Moral..., op. cit.

15 Idem. p. 166.

16 Ver P. D. Shaw, "Medicine and the Market...", op. cit. 
portamento altruísta se expandir por toda a sociedade, pois trata-se de um bem escasso. Do ponto de vista econômico, seria "irracional" que nos privássemos de um benefício para aumentar o benefício de outros. Entretanto, pondera Shaw, "se A é desejado por mim, não se segue daí que seja desejado para mim. Eu posso desejar o benefício de outrem". ${ }^{17}$ Em todo ato de doação ( ift, em geral), quem doa não o faz sem receber ou sentir algum benefício, mas em muitos casos, esse benefício não compensará a "perda de benefício", ou o custo, em que incorreu ao doar. Assim mesmo, doa-se. Para Shaw, uma sociedade que estimula a doação voluntária e não-remunerada está alicerçada na própria possibilidade de o comportamento altruísta, de modo geral, escapar às restrições que regulam o comportamento humano em relação a bens escassos.

Não é difícil tomar partido em uma discussão de princípios. A filosofia moral de Richard M. Titmuss é cativante na defesa da justiça redistributiva, seu modelo ideal de sociedade é generosamente socialista e democrático (a Good Society, de Robert Bellah, é, hoje, uma variante daquele modelo no Primeiro Mundo) e seu conhecimento empírico das mais diversas áreas de política social projetou-o definitivamente como um mestre, decorridos 20 anos de sua morte. ${ }^{18}$ No entanto, quem compartilhar dos princípios e propostas de Titmuss terá de conviver com a vulnerabilidade de algumas de suas análises e conclusões - este é, justamente, o caso de seu estudo sobre os sistemas hemoterápicos, cuja fragilidade se deve, em grande parte, ao próprio pioneirismo do estudo e à complexidade e amplitude inegáveis do projeto de pesquisa que desenvolveu.

Sabe-se que a hepatite pós-transfusional em países como os Estados Unidos e a Inglaterra atraiu a atenção da opinião pública e a preocupação das autoridades sanitárias durante pelo menos duas décadas. O estudo pioneiro de Richard Titmuss veio a público justamente na interseção delas, em 1971. The Gift Relationship não trouxe apenas mais vigor à militância desse velho guerreiro contra as políticas meramente residuais do governo e em favor das

17 Idem, p. 169, ênfases no original.

18 Entre cientistas sociais a entrada de Titmuss no Brasil se deu por vias tortas. Sua tipologia de políticas sociais, anterior a 1973 (ano de sua morte), foi incorporada pelo italiano U. Ascoli em 1984, e a este último tem sido equivocadamente atribuída a paternidade da tipologia. Segundo Titmuss, os modelos de política social classificam-se em residual, meritocrático e institucional redistributivo. Ver R. M. Titmuss, Social Policy (edição póstuma de B. Abel-Smith e K. Titmuss), Nova Iorque, Pantheon Books, 1974, esp. pp. 30-2. 
políticas sociais redistributivas e da presença ativa do Estado nesse campo. Mais que isso, para além das farpas entre civil servants e acadêmicos, a defesa intransigente de Titmuss dos sistemas hemoterápicos que privilegiassem as "relações altruístas", e assim tornassem mínima a incidência de hepatite transfusional, acabou por afetar diretamente o próprio funcionamento daqueles sistemas no Primeiro Mundo, e nos Estados Unidos em particular. Este ponto já foi salientado anteriormente; o que queremos chamar a atenção, agora, é para o novo período de avaliação e reformulação dos sistemas hemoterápicos, ocorrido a partir dos anos 80 , e que outra vez reacendeu o interesse em torno das análises e propostas contidas em The Gift Relationship.

O surgimento da Aids, em meados da década de 80 - precisamente, a contaminação transfusional pelo HIV - , provocou uma reavaliação das análises e propostas de Titmuss, e pôs em evidência a distância, ou pelo menos o descompasso, entre dois níveis de fenômenos: a discussão filosófica sobre altruísmo e sociedade, de um lado, e a discussão médica e organizacional sobre doação de sangue, sistemas hemoterápicos e contaminação transfusional, de outro. Como veremos na próxima seção, a literatura mais recente tornou duvidosa a correlação, central para o argumento de The Gift Relationship, entre altruísmo, doação não-remunerada e baixo índice de doenças transfusionais.

Aparentemente, as evidências trazidas por Titmuss são insuficientes para as conclusões que tirou. Para aqueles que compartilham de seus ideais de organização social, em sentido amplo, fica difícil, depois da discussão dos anos 80, deduzir daqueles ideais as propostas concretas de política pública para a hemoterapia. Parece claro, hoje, que se devam examinar favoravelmente propostas distintas, em maior ou menor grau, das de Titmuss e que se aproximam das idéias de Kenneth Arrow , sob pena de se ferir. em nome da adesão a este ou aquele princípio de organização social, a ética da responsabilidade social. Em outras palavras, seria eticamente inaceitável que primeiro procurássemos recuperar a unidade entre os dois planos do pensamento de Titmuss (os níveis da filosofia moral e da política social). mediante uma releitura de seus textos, para só então adotarmos medidas estratégicas de combate a doenças transfusionais como a Aids.

Ao apontar as barreiras organizacionais e sociais que impõem reformulações urgentes aos sistemas hemoterápicos do Primeiro Mundo, a literatura que apresentamos a seguir torna difícil, hoje, a aceitação in totum das propostas de Titmuss. A passagem dos princípios às propostas não poderá ser feita sem levar em conta as questões suscitadas por essa literatura, de funda- 
mental importância para a reavaliação dos sistemas hemoterápicos não só no Prımeiro Mundo. mas também em países como o Brasil. É desses estudos recentes que trata a próxima seção.

Dois importantes trabalhos, um de 1988 e outro de 1989, resumem algumas questões prementes da literatura internacional sobre o sangue, a partir do surgimento da Aids. O primeiro, que resenharemos a seguir, de autoria de James P. Isbister, médico do Departamento de Hematologia do The Royal North Shore Hospital em Sydney. Austrália, focaliza aspectos organizacionais e técnicos de diferentes "paradigmas" de serviços hemoterápicos. ${ }^{19} \mathrm{O}$ segundo, de Harvey M. Sapolsky, professor de Políticas Públicas do Massachusetts Institute of Technology - MIT, Estados Unidos, aborda diretamente as posições de Richard Titmuss, destacando os temas do altruísmo. doação de sangue e contaminação pós-transfusional ${ }^{20}$ Este é um texto mais claramente político, diferentemente do artigo de Isbister, que poderíamos classificar como "profissional".

A dimensão organizacional. Nas décadas que precederam a propagação da Aids, a crítica à excessiva descentralização e à falta de coordenação dos serviços de sangue de um país, a defesa da doação voluntária e do fornecimento de sangue ou seus derivados como bens "livres", tornaram-se símbolos de uma sociedade civilizada, particularmente entre os europeus. ${ }^{21} \mathrm{~A}$ própria Resolução da OMS (WHA28.72), ${ }^{22}$ já citada, é um exemplo importante de tais posições.

No entanto, esses pontos de vista começaram a ser revistos durante a década de 80 , sob o impacto da Aids. Já não se faz uma defesa intransigente

19 J. P. Isbister, "The Paradigm Shift in Blood Transfusion", The Medical Journal of Australia, vol. 148,1988

20 H. M. Sapolsky, "Aids. Blood Banking and the Bonds of Community", Deadalus, vol. 118, n 3. verão de 1989. pp. 145-63.

21 Nos Estados Unidos. ainda que se tenha difundido muito a doação voluntária e a distribuição gratuita de sangue por hemocentros não lucrativos, os serviços ainda se caracterizam por excessiva autonomia. Só recentemente, em maio de 1991, o conselho diretor da Cruz Vermelha anunciou a uniformização do sistema de coleta, armazenamento e distribuição. Até então, cada um de seus 53 núcleos possuía um padrão próprio de controle de qualidade do sangue. Essa excessiva descentralização se reflete até mesmo na inexistência, até aquela data, de um banco ou sistema nacional de dados hemoterápicos: Ver Jornal do Brasil, "EUA Anunciam Mudança nos Bancos de Sangue", 21/5/1991, p. 12.

22 Organización Mundial de la Salud, Toma, Fraccionamiento..., op. cit. 
das qualidades do mercado, como fizeram Cooper e Culyer, mas reflete-se sobre os pontos fracos dos sistemas centralizados diante da ameaça da Aids. Essa revisão de conceitos se revela no trabalho de James Isbister, em 1988, e prossegue ainda hoje no Primeiro Mundo. Já não se postula a centralização dos serviços, mas sim a uniformização dos padrões adotados em outras palavras, defende-se a coordenação dos serviços, não sua centralização. ${ }^{23}$

O artigo "A Troca de Paradigma na Transfusão Sanguínea", de James P. Isbister ${ }^{24}$ chama à atenção para uma distorção dos sistemas centralizados: eles teriam se desenvolvido mais em conseqüência das demandas do próprio sistema do que por conta das necessidades dos pacientes. Vejamos como Isbister constrói esse argumento.

Os procedimentos de anticoagulação que tornaram possível a separação entre doador e receptor e, mais tarde, o espetacular avanço nas técnicas de fracionamento de sangue e terapia com seus derivados, não teriam sido acompanhados, segundo o autor, por um aprofundamento dos conhecimentos clínicos sobre o tema. Esse tipo de saber teria se restringido aos profissionais dos bancos de sangue, cuja preocupação central é com a coleta de quantidades adequadas de sangue e com o suprimento. Diferentemente dos pacientes da rede hospitalar, que só raramente se organizam em grupos de pressão, a população hemofílica está bem organizada na Austrália e reclama dos bancos de sangue uma preocupação constante com o suprimento maciço de fator VIII de coagulação sanguínea ou de albumina.

Assim, argumentos tais como, "os concentrados de células vermelhas devem ser usados de modo a garantir um suprimento adequado de fator VIII para pessoas com hemofilia", tornaram-se moeda corrente. No entanto, segundo Isbister, proposições como essa, ainda que válidas do ponto de vista da atenção à saúde daquele grupo, devem ser repensadas de uma perspectiva clínica, isto é, do atendimento aos interesses de outros grupos além dos hemofílicos. Por exemplo, a sociedade civil não desenvolveu estratégias de defesa para certos grupos de pouca voz junto aos bancos de sangue, como os pacientes de traumas, que demandam componentes de sangue apropriados para suas terapias.

23 O caso da França é exemplar. A excessiva centralização da rede oficial de transfusões, sob o comando do Centro Nacional de Transfusões Sanguíneas, tem sido apontada como responsável pelo fornecimento de sangue contaminado entre 1983 e 1986, que provocou a morte de 256 hemofílicos e a infecção pelo HIV de mais de 600 receptores. Ver $O$ Globo, 2/3/1992: Rádio Jornal do Brasil-AM, Informe Especial de 26/10/1992 e 27/10/1992, nossa gravação em tita cassette.

24 J. P. Isbister, “The Paradigm Shift...", op. cit., pp. 306-8. 
O desenvolvimento de uma lógica de serviços mais ligada às necessidades de transfusão (e de algumas minorias como os hemofílicos) do que às exigências do atendimento hospitalar teria gerado distorções, tais como o baixo incentivo que os sistemas centralizados dão ao desenvolvimento da terapia por componentes na prática hospitalar. Dentro dessa lógica da centralização, as transfusões autólogas derivadas da mesma pessoa não chegaram a ganhar espaço na prática médica, porque seus custos teriam de ser arcados pelo hospital ou pelo paciente, enquanto a transfusão homóloga derivada de pessoas diferentes, mas de grupos sanguíneos compatíveis, apesar de envolver maiores riscos, é "gratuita" e mais difundida.

A viabilidade e as limitações das transfusões autólogas são discutidas em dois textos de natureza técnica: um de autoria de Pearl T. C. Toy et alli ${ }^{25}$ e outro de G. F. Leparc et alli. ${ }^{26}$ Nesses artigos são descritos os métodos de transfusão autóloga: a hemodiluição, a recuperação do sangue (na operação e pós-operação) e o pré-depósito com estocagem. Esta última é a modalidade mais comum nos Estados Unidos.

Uma pesquisa de abrangência nacional nesse país, discutida pelos autores citados, estudou cerca de 5 mil pacientes indicados para cirurgias eletivas em 18 hospitais. Verificou-se, a partir de projeções, que $72 \%$ das necessidades de glóbulos vermelhos teriam sido supridas por sangue autólogo, caso todos os pacientes aptos tivessem pré-depositado seu sangue. Por outro lado, em contraste com as transfusões autólogas, estima-se que pelo menos $10 \%$ das transfusões homólogas provocam complicações como urticária, febre, reações hemolíticas e a transmissão de doenças infecciosas entre elas a hepatite e a Aids. O emprego de sangue autólogo poderia reduzir aquela taxa. Entretanto, seu alto custo, além de outras dificuldades, têm reduzido sua utilização nos serviços transfusionais. Mesmo para o futuro, não representa uma solução definitiva ou exclusiva para os problemas transfusionais. ${ }^{27}$

Para Isbister, cabe hoje repensar os sistemas hemoterápicos, ${ }^{28}$ identificando-se os serviços relacionados ao hospital e seus pacientes, e direcionan-

$25^{\circ}$ P. T. C. Toy et alli, "Predeposited Autologous Blood for Elective Surgery", The New England Journal of Medicine, vol. 316, $\mathrm{n}^{\circ}$ 9, 1987, pp. 517-20.

26 G. F. Leparc et alli, "Autologous Transfusion: A Community Blood Bank", Southern Medical Journal, vol. 80, no $3,1987$.

27 No Brasil, as experiências com transfusões autólogas têm ficado restritas aos serviços particulares de primeira linha e a alguns serviços públicos de excelência.

28 Na Austrália, as atividades hemoterápicas são controladas pelo Serviço de Transfusão da Cruz 
do-se o financiamento também para tais serviços. A provisão de transfusões autólogas, de concentrados de leucócitos granulares, de concentrados de plaquetas de um só doador, de sangue inteiro fresco, a permuta de plasma e certos procedimentos de aférese deveriam ser incluídos nessa categoria relacionada às necessidades hospitalares. Por outro lado, caberia aos serviços centralizados a responsabilidade pela provisão de concentrados de hemácias, plasma fresco congelado, soluções de proteína plasmática, concentrados de plaquetas de doadores múltiplos, preparados de imunoglobulina e concentrados de coagulação.

Ainda no citado trabalho, Isbister sugere uma série de ajustes para os sistemas hemoterápicos modernos. As mudanças propostas referem-se à combinação adequada entre a pressão que o sistema de doação deve aceitar e a que os receptores devem exercer; à definição sobre que tipo de serviços seriam centralizados e quais descentralizados; às áreas onde a iniciativa privada poderia funcionar, em um conjunto coordenado de atividades, ao lado do setor público ou beneficente. ${ }^{29}$ Por outro lado, o artigo não aborda a questão da produção de hemoderivados em escala industrial, ainda não solucionada no Primeiro Mundo, como atestam as importações de plasma do Terceiro Mundo e as especulações sobre as possibilidades de manutenção de estoques por meio de um Euroblood Program na esteira de criação da Comunidade Européia.

Altruísmo e política pública. $\mathrm{O}$ artigo que analisamos a seguir, "Aids, Bancos de Sangue e Laços Comunitários", ${ }^{30}$ de Harvey M. Sapolsky, dá menor ênfase às questões organizacionais e maior destaque aos aspectos centrais da discussão de Titmuss. A questão fundamental para ele é a relação entre doação altruísta de sangue e contaminação transfusional. Sua conclusão básica difere daquela que Titmuss apresentou, e a partir de tal discordância Sapolsky vai defender a adoção de salvaguardas contra a contaminação

Vermelha, que, segundo Isbister, teve desde cedo uma ação fïrme, excluindo doadores de grupos de risco, e transformando a Austrália em um dos primeiros países a introduzir os testes que permitiram reduzir a incidência da Aids em seu sistema hemoterápico. Parte das reflexões do autor se deve, provavelmente, à polêmica que se armou na Austrália em torno da entrada em funcionamento do Private Blood Bank of Australia.

29 Quanto às condiçōes de funcionamento e padrōes de qualidade dos bancos de sangue, ao tamanho dos serviços e às possibilidades de automação, ver L. I. Friedman et alli, "The Status of Automation and Data Processing in the United States Blood Banking Community", Transfusion, vol. 26, 1986, pp. 514-8.

30 H. M. Sapolsky, “Aids, Blond Banking...”, op. cit., pp. 145-63, tradução nossa. 
pelo HIV, que incluem a doação remunerada. "Doenças", diz ele, "podem espalhar-se por atos altruístas ou egoístas".31

Sapolsky defende a necessidade de repensarmos, além dos aspectos organizacionais, o próprio paradigma da doação voluntária. Seu artigo apresenta, inicialmente, um histórico das reações suscitadas nos EUA pela "descoberta" da Aids transfusional, em meados de 1982; a partir daí, volta-se para os mecanismos e estratégias que devem ser adotados para reduzir ou eliminar a infecção decorrente de transfusões sanguíneas.

De início, o autor indica que não apenas no sistema descentralizado dos EUA, mas em quase todos os sistemas centralizados, a provisão de sangue para transfusões é uma responsabilidade da comunidade. Sem saber quem são os receptores e sem uma compensação financeira direta, aqueles que podem doam sangue para aqueles que precisam. Existe, portanto, um componente altruísta em todos os sistemas hemoterápicos.

Em janeiro de 1983 houve um encontro nos EUA entre autoridades federais e técnicos da área, no qual a preocupação com a infecção do sangue pelo vírus da Aids era patente. Nessa reunião, discutiu-se uma proposta para se excluir membros de grupos de alto risco do pool de doadores, que terminou por gerar um confronto entre profissionais e instituições que coletam plasma e os que coletam sangue total.

O setor de plasma, controlado por grandes indústrias farmacêuticas que pagam seus doadores, indicou a intenção de adotar os protocolos de exclusão e interromper a coleta de plasma em grupos de alto risco. ${ }^{32} \mathrm{O}$ setor de bancos de sangue, que coleta e processa sangue integral das doações para transfusão, é composto em sua maioria por centros regionais não-lucrativos e bancos de sangue hospitalares que não pagam seus doadores. Nacionalmente, ele é composto por três organizações que freqüentemente apresentam membros comuns: a Cruz Vermelha Americana, a Associação Americana de Bancos de Sangue (AABB) e o Conselho Comunitário dos Hemocentros. Este grupo se mostrou relutante em acatar a proposta de exclusão dos doadores de alto risco, atrasando em alguns meses a ação governamental para regulamentar matéria nesse sentido.

31 Idem, p. 156.

32 Os fatores de coagulação para hemofílicos são elaborados a partir de pools plasmáticos compostos por cerca de 5 mil doações, e podem ser contaminados por um único portador do vírus da Aids. Cerca de $50 \%$ dos hemofílicos norte-americanos estão hoje infectados. Entre as vítimas mais graves de hemofilia, necessariamente mais expostas ao fator, o grau de infecção é estimado entre $70 \%$ e 90\%. Ver H. M. Sapolsky, “Aids, Blood Banking...”, op. cit., p. 147. 
Diferenças estruturais ajudariam a entender, segundo Sapolsky, a diversidade de respostas e preocupações. As empresas de plasma são altamente competitivas e participam de um mercado internacional. As atividades de coleta de sangue integral têm como base a doação voluntária mulheres e minorias étnicas doam menos freqüentemente que homens brancos jovens. "Em muitas cidades americanas a comunidade gay foi uma coletividade acessível e bem-organizada com a qual, em repetidas campanhas, os bancos de sangue construíram boas relações, reconhecendo-a como uma boa fonte de doações" ${ }^{33}$ Este setor é dominado por agências de coleta que não visam ao lucro e têm monopólio local, suprindo todo ou quase todo sangue transfundido em uma região. A Cruz Vermelha, a AABB e o Conselho Comunitário dos Hemocentros coordenam políticas que, segundo Sapolsky, permitem a "oligopolização" das atividades, por meio da diminuição da competição entre aquelas agências. (Também os hospitais podem ser licenciados para suprir suas demandas, mas para a maior parte deles os obstáculos econômicos e profissionais desencorajam esta opção.)

O perfil dos coletores de sangue integral desenvolveu-se, sobretudo, a partir dos anos 70, com a enorme repercussão alcançada pelo trabalho de Titmuss. A opinião pública, no entanto, teria sido formada por argumentos equivocados. Segundo Sapolsky, os que coletavam comercialmente e remuneravam os doadores já tinham voltado sua atenção para o mercado de plasma, em crescimento acelerado em virtude da descoberta de importantes hemoderivados. Com isso, na ausência dos interesses do setor de plasma, a ação da Cruz Vermelha, da AABB e dos Hemocentros, visando ao monopólio do sangue nos EUA, teria sido facilitada. Por outro lado, o argumento de que a hepatite transfusional e a remuneração de doadores estão correlacionadas é falso. Isto se verifica não só pelo fato de que, apesar de todas as mudanças no sistema norte-americano de doação, as taxas de hepatite transfusional baixaram muito pouco a partir da década de 70, como também pela constatação de que há países, como a Suécia, onde as doações são pagas e os índices de doenças ligadas à transfusão são baixos.

Mas Sapolsky apresenta, ainda, outro argumento poderoso: Titmuss desconhecia que, além da doação voluntária por ele enfatizada, precauções extras foram tomadas pelos serviços de transfusão ingleses para não coletar em áreas com altas taxas de imigrantes do Terceiro Mundo, onde a hepatite é endêmica. Além disso, rotulavam as doações pela "raça" do doador e não

33 Idem, p. 148, tradução nossa. 
transfundiam sangue doado por paquistaneses, africanos e outros imigrantes de países pobres. Titmuss teria ainda ignorado que algumas das principais instituições médicas dos EUA, a Clínica de Mayo e o Hospital Geral de Massachusetts entre elas, possuíam doadores pagos e baixas taxas de hepatite transfusional, decorrentes de uma cuidadosa seleção de doadores. Desse modo, a baixa taxa de hepatite transfusional que Titmuss observou na Inglaterra teria, segundo Sapolsky, mais a ver com o tipo de sangue que estava sendo transfundido do que com o fato de os doadores não serem pagos. Assim, não seria de surpreender que a generalização da doação voluntária entre os setores que coletam sangue integral nos EUA tenha tido pequeno efeito sobre as taxas de hepatite transfusional.

Feitas essas críticas ao "monopólio" dos coletores de sangue integral nos EUA e ao paradigma da doação voluntária, Sapolsky delineará a dimensão do impacto da Aids sobre o sistema de bancos de sangue norte-americano e indicará algumas medidas profiláticas a serem tomadas.

Do total de casos de Aids notificados nos EUA, 3\% são atribuídos a terapêuticas em que se utiliza sangue. Os dirigentes de bancos de sangue foram inicialmente grandes entusiastas dos testes anti-HIV e proclamavam que, com seu emprego, os dias da contaminação transfusional estavam contados. A taxa de erro dos testes foi estimada inicialmente em 1 por 1 milhão; logo depois, foi corrigida para 1 por 300 mil e em seguida 1 por 100 mil. Atualmente é estimada entre 1 por $10 \mathrm{mil}$ (ou 1 por 5 mil) e 1 por $100 \mathrm{mil}$. Em um quadro de aproximadamente 3,5 milhões de transfusões anuais, isto significa que elas serão responsáveis diretamente por 35 a 700 novos casos de Aids por ano. ${ }^{34}$

Diante desse panorama, levando em conta a dificuldade de se avançar nas pesquisas sobre substitutos artificiais do sangue e a limitação ao crescimento das transfusões autólogas (que não podem satisfazer mais que $10 \%$ da demanda, dada a imprevisibilidade das necessidades e a debilidade de muitos pacientes), Sapolsky sugere o emprego dos seguintes expedientes: (a) incentivar as transfusões cruzadas (para receptores designados previamente, que trazem o doador); (b) obter sangue para transfusão em localidades de baixa incidência de Aids; (c) pagar aos doadores, com o que se poderia criar painéis de doadores freqüentes, testados e acompanhados clinicamente; (d) incentivar a doação entre mulheres, pessoas de meia-idade ou outros doadores menos sujeitos a serem portadores do HIV.

34 Idem, p. 153. 
Além da urgência com que essas medidas devem ser implementadas pois, como lembra Sapolsky, dependendo da composição do pool de doadores as conseqüências do acaso em uma comunidade podem ser dramáticas, o poder público deve estar atento para que a segurança oriunda dessas medidas seja garantida a todos. De fato, não há como ignorar esta advertência do autor: "[...]quanto maior o número de pessoas que se retirarem do pool comunitário para fazer arranjos privados que as protejam, mais se torna provável que o pool comunitário assim reduzido se torne crescentemente desvantajoso para aqueles que não tenham outra alternativa senão continuar utilizando-o". "35 Uma política pública precisaria, assim, avaliar cuidadosamente as estruturas e os procedimentos organizacionais que tornassem o uso do sangue mais seguro para todos.

Algumas observações preliminares podem ser feitas com base na discussão precedente. Desde logo, note-se que, ao contrário do que Richard Titmuss previa, o sistema altruísta impõe, no momento, riscos consideráveis aos receptores de sangue no Primeiro Mundo. ${ }^{36}$ Como se viu, um sistema que remunera doadores, como é o caso do setor de produção de hemoderivados nos Estados Unidos, que adota procedimentos de screening rigorosos, além de testes de alta sensibilidade para diagnosticar sangue contaminado, é no momento mais seguro (mais eficiente, diria Kenneth Arrow) que o sistema de coleta que não remunera seus doadores, baseando-se fundamentalmente na aplicação de testes para barrar os possíveis portadores de doenças como a Aids ou a hepatite.

Essa observação preliminar nos leva a indagar dos efeitos do paradoxo da "contaminação altruísta" nos EUA sobre os sistemas hemoterápicos no Terceiro Mundo. De que modo essa situação paradoxal pode afetar o Brasil em particular? Ao que tudo indica, o Brasil apresenta o pior cenário possível. A "auto-seleção", ${ }^{37}$ em busca de teste para Aids, já é responsável, entre nós. por uma participação crescente de pessoas de grupos de risco entre novos doadores voluntários; a proporção de doadores não-remunerados, das classes média e alta (com menor risco de contrair a doença de Chagas, sífilis e

35 Idem, p. 157.

36 Correm risco também os doadores por plasmaférese se as hemácias de um primeiro doador que tenha doado sangue contaminado forem injetadas no segundo doador.

37 Por "auto-seleção" entende-se a maior probabilidade de pessoas de "grupos de risco" doarem sangue para obter o teste de Aids. 
malária), é baixíssima - esse quadro revela uma situação ainda pior que a norte-americana no que tange aos riscos da doação altruísta proveniente de grupos de risco.

Também estamos em nítida desvantagem em relação às condições em que o sangue é remunerado: bancos clandestinos de sangue em certas áreas de extrema pobreza do Sudeste, como a Baixada Fluminense, atraem doadores para os quais a compensação financeira é um meio (desesperado) de sobrevivência; a indústria de hemoderivados compra boa parte de sua matéria-prima dessas áreas de alto risco. Diferentemente dos Estados Unidos, quem compra sangue no Brasil o faz mediante de critérios pouco seguros, na melhor das hipóteses; na pior, usa critérios criminosos.

Quanto ao dilema da compensação financeira versus doação altruísta, o quadro internacional parece tomar um novo rumo diante do impacto da Aids. Como se fosse uma decisão estratégica e não uma decisão de princípio pois esta última a nosso ver excluiria a compensação monetária , mecanismos de pagamento poderão difundir-se, seja com base no modelo norte-americano (remuneração feita pelo setor privado), seja espelhando-se no modelo sueco (pelo setor público), tentando reduzir a zero os casos de "falsos negativos" nos testes anti-Aids, por meio do maior controle que o pagamento de doadores cadastrados permite. Além disso, a remuneração por parte de serviços de primeira qualidade poderá representar um estímulo para que grupos populacionais de menenor risco, até hoje infensos à doação, sintam-se estimulados a doar.

A situação brasileira exige a adoção de salvaguardas mais rigorosas. De um lado, a fiscalização deverá pôr fim à coleta e compra clandestina de sangue (retirado, como se sabe, de grupos populacionais marginais e subnutridos). De outro, no quadro político atual de tentativa de revalorização da rede pública hospitalar e de assistência médica, cabe refletir sobre a conveniência do emprego do "modelo sueco", que tornaria viável a compensação financeira a trabalhadores urbanos e outros grupos de doadores acompanhados rigorosamente pelos serviços de hemoterapia. Ao mesmo tempo, as campanhas para que as classes médias passem a doar sangue devem ser retomadas com engenho e arte pelas autoridades sanitárias. A doação altruísta por parte de todos os segmentos da população deve e pode concretizar-se, ainda que em um futuro longínquo. ${ }^{38}$

38 Faz-se necessário um estudo abrangente e sistemático dos fatores que favorecem ou restringem a doação altruísta no Brasil, particularmente entre as classes média e alta. Tal estudo deverá levar em conta tanto a pluralidade regional (por exemplo, deverá abranger centros como São 
De modo geral, a politização do sangue no Primeiro Mundo distanciase do que se passa no Brasil em um ponto crucial: aqui a discussão é. em primeiro lugar, política e ideológica, com ênfase no segundo termo; lá, observam-se duas fases: na primeira, pré-Aids, o debate público e acadêmico centrou-se em aspectos normativos ou de filosofia moral; na segunda, de meados da década de 80 até hoje, enfatiza-se o aspecto organizacional.

No Primeiro Mundo, atualmente, não estão mais em jogo aspectos normativos quanto à superioridade/inferioridade de sistemas públicos ou privados como na abordagem pioneira de Titmuss, mas discute-se, primordialmente, a dimensão organizacional de tais sistemas. Em outras palavras, avalia-se em que medida este ou aquele sistema se adapta melhor às necessidades de operação coordenada dos recursos e serviços para a população. Esta é, pois, a questão central: em que esferas de atuação (produção de hemoderivados, coleta de sangue, atendimento das demandas hospitalares gerais e de grupos específicos da população como os hemofílicos etc.) os serviços públicos e privados são mais eficientes? De que modo, e em que áreas de operação, tais serviços podem ser complementares? Em que áreas devem ter autonomia? Deve-se aceitar que a autonomia dê lugar à hegemonia de um setor sobre o outro, até sua completa exclusão?

De modo geral, em um futuro próximo podemos antever um certo distanciamento das políticas públicas, tanto das idéias de um autor clássico como Titmuss, quanto das posições de Arrow e Sapolsky. As políticas públicas deverão aproximar-se de um consenso quanto a esse ponto: a descentralização de serviços particulares e filantrópicos, na ausência de formas de controle e participação do Estado (que até hoje caracteriza o sistema norteamericano), pode ter efeitos tão prejudiciais quanto um sistema estatal centralizado ("à francesa") sobre a eficiência e o alcance social das atividades hemoterápicas.

No Brasil, pode-se esperar que as discussões excessivamente ideológicas do tema público versus privado sejam superadas, e que no day after os "atores" envolvidos — sejam profissionais da área pública ou privada, sejam militantes de movimentos sociais ou representantes do Estado - possam direcionar seus esforços para a solução de problemas substantivos da atividade hemoterápica. Nosso sistema hemoterápico em particular o conjunto mais articulado de atividades posteriores ao Pró-Sangue de 1980 tem progredido, recentemente, em conexão com as diretrizes do Sistema Unificado de

Paulo, Rio de Janeiro e Brasília), como a pluralidade de métodos de estudo (da Sociologia e da Psicologia Social). Os autores do presente trabalho preparam projeto de pesquisa neste sentido. 
Saúde - SUS, rumo à descentralização de recursos e serviços. Há, é claro, o espírito centralizador que perdura nas políticas previdenciária e de saúde pública, e que terá de ser eliminado. Em outras palavras, para fugir ao mesmo tempo à desorganização que resulta da excessiva autonomia dos serviços e à camisa-de-força que advém de um comando central onipresente, a coordenação dos recursos e serviços é a palavra de ordem. O sistema hemoterápico brasileiro, do qual a criação e difusão de hemocentros em todas as regiões do País constituem peças-chave, poderá caminhar bem nesse particular.

Se os obstáculos de ordem organizacional não são insuperáveis, onde residem, então, os problemas que dividem os "atores" da hemoterapia em campos opostos? Um primeiro problema é, a nosso ver, a visão partidária e ideológica, de cunho retórico, sobre "público versus privado". Um segundo problema é a incapacidade empresarial, incluindo-se aí a falta de ética, de setores ligados à produção de hemoderivados no País. A matéria publicada na revista Ciência Hoje, em abril de 1989, demonstra as falhas graves do setor industrial, constatadas durante inspeção dos órgãos de vigilância sanitária. ${ }^{39}$ Esses são dois pontos de estrangulamento nos rumos futuros da hemoterapia no Brasil. Para superar tais obstáculos e, mais ainda, para reorientar nosso debate de um ponto de vista amplo, abrangendo também a regulamentação ou revisão da matéria constitucional de 1988, parece evidente a contribuição que a literatura internacional poderá prestar à escolha dos rumos da hemoterapia brasileira.

\section{RESUMO}

\section{A Politização do Sangue no Primeiro Mundo}

Terceiro de uma série dedicada ao estudo da "questão do sangue" sob o ângulo das políticas sociais e do interesse público, o presente artigo aborda alguns temas importantes da literatura internacional. Uma característica perversa do paroquialismo dos debates, no Brasil, entre sanitaristas e hemoterapeutas, movimentos sociais e aparelhos burocráticos, congressistas e grupos de pressão, é justamente o desconhecimento da literatura internacional.

39 Ver o trabalho de S. H. Ferreira (editor convidado), "O Brasil Precisa de Sangue", Ciência Hoje, vol. 52, nº 9, abril de 1989, pp. 44-61. Os dados que apontam as irregularidades do setor industrial estão em M. C. Adati e R. S. da Cunha. Situação da Produção de Hemoderivados no Brasil, relatório de pesquisa apud S. H. Ferreira, "O Brasil Precisa...". op. cit.. p. 58. 
Ao discutir certos temas dessa literatura, procuramos trazer para o debate nacional alguns autores estrangeiros que tratam de aspectos institucionais, organizacionais e técnicos da maior importância para a montagem, operação e correção dos problemas de um sistema hemoterápico. O próprio pioneirismo dos trabalhos internacionais é digno de nota. Diferentemente de seus colegas brasileiros, os cientistas sociais europeus e norte-americanos dedicaram-se ao estudo da doação de sangue e da hemoterapia muito antes do aparecimento da Aids. A obra clássica sobre o tema, objeto de especial atenção no presente artigo, é The Gift Relationship, publicada na Inglaterra em 1971. Richard M. Titmuss, seu autor e mestre em estudos de política social na "London School", defende a doação altruísta, não-remunerada, como uma salvaguarda contra a hepatite pós-transfusional e como um instrumento de expansão do comportamento altruísta e dos laços comunitários em qualquer sociedade. $\mathrm{O}$ artigo apresenta, igualmente, as críticas ao trabalho de Titmuss que vieram do outro lado do Atlântico, particularmente as de Kenneth Arrow (Harvard) e Harvey Sapolsky (MIT), que defendem. em nome de um ideário neoliberal e de necessidades operacionais consideradas intrínsecas à atividade hemoterápica, a máxima liberdade de opções inclusive a liberdade de conceder e receber compensação financeira pelo sangue doado e transfundido. Sapolsky, em especial, faz considerações importantes sobre a garantia adicional que painéis de doadores pagos podem representar contra as doenças transfusionais - lembrando não apenas o caso dos EUA como o da Suécia - , por permitirem um cuidadoso acompanhamento médico. O propósito deste artigo, além do exame do quadro internacional que gerou a controvérsia Titmuss versus Arrow e Sapolsky, é tirar lições para o caso brasileiro. De um lado, o Brasil reproduz do cenário norte-americano o exemplo costumeiro da doação e transfusões pagas. Lá, a formação de painéis de doadores pagos e cuidadosamente monitorados vem representando uma defesa adicional contra a contaminação do sangue. Aqui, entretanto, a atividade comercial está, não raro, oculta sob a cortina da atividade filantrópica e, mais freqüentemente, responde pela maior parte dos casos de contaminação do sangue no País. De outro lado, as doações voluntárias que, nos países desenvolvidos, provêm em grande parte das classes média e alta, no Brasil originam-se primordiamente das camadas mais pobres - justamente os grupos de mais baixo padrão nutricional e sanitário, e menos aptos a doar. Além disso, de modo geral a população brasileira doa menos sangue do que, por exemplo, os ingleses. O presente trabalho propõe, assim, uma questão básica: de que modo as discussões sobre os problemas do sangue no Brasil, particularmente a regulamentação da matéria constitu- 
cional de 1988, podem se beneficiar das idéias e polêmicas que brotaram em países do Primeiro Mundo? Se o ideário neoliberal de um Sapolsky, por exemplo, não cativar o leitor brasileiro, suas propostas ou programas de ação poderão surpreender pela aplicabilidade. $O$ inverso talvez se dê em relação a Titmuss, cuja força de argumentação reside menos nas propostas de policy (debilitadas pela crítica desferida por Sapolsky) do que em sua generosa defesa de uma ética social redistributiva que, simultaneamente, se beneficie dos laços comunitários e os consolide. Uma política hemoterápica para o Brasil deverá tirar partido dessa profunda tensão entre valores éticos e propostas de ação.

\section{ABSTRACT \\ From Titmuss to Sapolsky: Perspectives on Human Blood and Social Policy}

Unlike their fellow Brazilians, social scientists in Europe and North America paid close attention to issues of blood donation and policy many years before the AIDS pandemic. This article is partly an attempt to review such pioneering studies. Among the most important contributions from the social sciences was Richard M. Titmuss's path-breaking study on The Gift Relationship (with the subtitle From Human Blood to Social Policy), published in England in 1971. Based on a 1967 survey of blood donors in England and on comparable data from other developed countries, it is a classic study of moral philosophy and public policy. Through this book, Titmuss became known as a staunch supporter of voluntary, non-paid donations, which, in his view, contributed to decrease the risks of transfusion-related hepatitis, and, most important, helped promote altruistic behavior within the social systems. This paper summarizes Titmuss's ideas and policy proposals, and discusses some authors who, in subsequent years, endorsed both his ideas and policy recommendations. From an opposite battle field (in American soil), the article selects two representative papers by Kenneth Arrow and Harvey Sapolsky, who diligently attempt to criticize Titmuss's views. The authors present a different, neoliberal set of principles in support of a free market for blood and plasma, where paid donations for whole blood and plasma collection must be allowed. Harvey Sapolsky, in particular, argues that the creation of panels of paid, carefully monitored, blood donors may actually decrease the risks of contamination from hepatitis or AIDS. According to Sapolsky, Titmuss failed to see that the links between voluntary 
donations and transfusion-related hepatitis are unclear, and that even his 1967 survey data do not suggest the existence of any clear-cut relationship. For this reason, writes Sapolsky, it is also misleading to expect that unpaid donations will protect against AIDS. As the present paper tries to show, Sapolsky's analysis and proposals deserve careful consideration. They seem to represent a perfect case for an old dictum on "the creative power of the erroneous idea." His policy proposals seem perfectly sound, yet his moral philosophy - as much as Arrow's - is less convincing and enticing than Titmuss's. A related purpose of the article is to take some lessons from the international literature. In what ways are the various arguments on blood and social policy, summarized in the present article, relevant to the Brazilian debate? Unfortunately, petty politics and parochial interests have dominated the debate in Brazil, particularly in the Congress. In hopes that the Congress may be pressed to consider the real interests of the population in the future, this paper wishes to attract the attention of the professional groups and social movements involved in the fight against transfusion-related AIDS (which only 3 years ago accounted for $8 \%$ cases of the disease) to the technical and organizational issues discussed in the international literature. Specifically. the paper attempts to contribute to the current effort of revision of the legislation approved by the 1988 Constitution Assembly, which completely ignored crucial issues on the nature and operation of blood systems, such as those raised in the Titmuss-Arrow controversy.

\section{RESUME}

\section{La Politisation du Sang dans le Premier Monde}

Cet article est le troisième d'une série consacrée à l'étude de la "question du sang" prise sous l'angle des politiques sociales. Il aborde quelques thèmes importants de la littérature internationale en la matière. Un des aspects les plus pervers de la querelle de clochers qui, au Brésil, domine les débats entre sanitaristes et hémothérapeutes, mouvements sociaux et appareil bureaucratique, congressistes et groupes de pressions consiste justement dans la méconnaissance de la littérature internationale. C'est pourquoi, lorsqu'il analyse certains thèmes de cette littérature, le rédacteur s'efforce d'introduire dans le débat national quelques auteurs étrangers. Les aspects institutionnels, organisationnels et techniques qu'ils traitent sont de la plus haute importance pour ceux qui ont mission de monter et de mettre en opération un système d'hémothérapie ou d'en corriger les problèmes. Les travaux 
développés dans certains pays sont pionniers en ce domaine et il faut le souligner. Contrairement à leurs collègues brésiliens, les spécialistes européens et américains en sciences sociales se sont consacrés à l'étude du don de sang et de l'hémothérapie bien avant l'apparition du SIDA. L'oeuvre la plus classique à ce propos, qui fait l'objet d'une attention spéciale dans cet article, est The Gift Relationship, publiée en Angleterre en 1971. Richard M. Titmuss, son auteur qui est maître d'études en politique sociale de la "London School", défend le don altruiste, non rémunéré dans lequel il voit une protection contre l'hépatite post-transfusionnelle ainsi qu'un instrument d'expansion de comportements altruistes et de liens communautaires au sein de toute société. L'article présente aussi les critiques qui furent faite au travail de Titmuss et qui proviennent de l'autre côté de l'Atlantique, particulièrement celles Kenneth Arrow (Harvard) et de Harvey Sapolsky (MIT). Au nom d'un idéal néolibéral et de besoins opérationnels qu'ils considèrent intrinsèques à toute activité liée à l'hémothérapie, ces derniers défendent la plus grande liberté d'options, y compris la liberté de donner et de recevoir une compensation financière pour le sang donné et transfusé. Sapolsky fait en particulier des considérations importantes sur la garantie supplémentaire que des groupes de donneurs rémunérés peuvent représenter contre les maladies transfusionnelles. Il rappelle à ce propos le cas des USA et même celui de la Suède où les dons rémunérés rendent possible un accompagnement médical soigné. Mais cet article n'a pas seulement pour but de présenter un examen du cadre international qui a engendré la controverse entre Titmuss et Arrow ou Sapolsky. Il se propose aussi d'en tirer des leçons pour le cas brésilien. Si d'un côté le Brésil reproduit la situation nord américaine en ce qui concerne la rémunération des dons et des transfusions, d'un autre côté il ne dispose pas, comme dans les pays cités, de groupes de donneurs payés et soigneusement suivis, ce qui représenterait un moyen de défense supplémentaire contre la contamination du sang. Il n'est pas rare ici que sous le couvert d'une activité philanthropique se cache en fait une activité comerciale. C'est souvent elle qui réponde pour la plupart des cas de contamination du sang au Brésil. Par ailleurs, alors que dans les pays développés les dons volontaires proviennent en grande partie des classes moyennes et supérieures de la population, au Brésil il trouvent essentiellement leur origine au sein des couches les plus pauvres - justement celles qui, ayant les plus bas niveaux nutritionnels et sanitaires, sont les moins aptes à faire ce don. En outre, d'une façon générale, les brésiliens ont moins tendance à donner leur sang que les anglais par exemple. C'est pourquoi ce travail aborde une question fondamentale: en quoi les discussions sur les problèmes liés au sang au Brésil, 
particulièrement la réglementation de la matière constitutionnelle de 1988 . peuvent tirer profit des idées et des polémiques surgies dans les pays du Premier Monde? Si l'idéal néolibéral d'un Sapolsky n'offre guère de séduction au yeux d'un lecteur brésilien, ses propositions et ses programmes d'action ne manquent pas de surprendre par leur applicabilité. En ce qui concerne Titmuss, c'est peut-être le contraire qui se produit. La force de son argumentation réside moins dans ses proposition de policy (affaiblies par les critiques que leur a asséné Sapolsky) que dans sa défense généreuse d'une politique sociale redistributive qui prend appui sur les liens communautaires tout en les renforçant. C'est pourquoi une politique d'hémothérapie pour le Brésil se devra de tirer parti de cette profonde tension entre des valeurs éthiques et des propositions d'action. 